\title{
Effects of the pitch and duration of tones on EEG desynchronization'
}

\author{
D. E, BERLYNE AND R. M. NICKI ${ }^{2}$ \\ UNIVERSITY OF TORONTO
}

EEG waves were recorded while $S$ s were exposed to tones of four frequencies, equated for subjective loudness and lasting for 1, 2, or $3 \mathrm{sec}$. Mean duration of desynchronization was a U-shaped function of acoustic frequency and an increasing linear function of stimulus duration.

Both musical practice and everyday experience suggest that arousal may be affected by auditory pitch. There are grounds for suspecting that, in music, higher notes produce a more "exciting" or "emotional " effect (Berlyne 1960, pp. 172-173), but pitch is usually confounded with other variables, such as timbre, loudness, direction of change in pitch, and relative frequency of occurrence.

The present experiment was designed to compare effects of four tones of equal loudness butdiffering frequencies on one index of arousal or component of the orientation reaction, namely the duration of EEG desynchronization. A second objective was to ascertain how the duration of desynchronization varies with the duration of a tone.

Method

EEG was recorded by means of a Grass Model V Polygraph from an electrode on the left occipital area with an electrode clipped to the left ear lobe as ground. Apart from the differences noted, the recording procedures, criteria for discarding Ss, and scoring techniques were the same as those used in a previous experiment on effects of visual complexity (Berlyne \& McDonnell, 1965).

Tones of four frequencies-200,400,800 and 1600 cps-were used. These represent the same note (between $G$ and $G^{\#}$ ) in each of four consecutive octaves. They were presented through a pair of earphones and came from three sinusoidal-tone generators through an electronic switch controlled by a Hunter timer.

The intensities of the tones were set to give a reading of $70 \mathrm{db}$ with weighting $\mathrm{B}$ on a General Radio Type 1555-A Sound-Survey Meter. Weighting B, prescribed by the American Standard Association, is designed (Peterson \& Gross, 1963) to follow the FletcherMunson (Fletcher \& Munson, 1933) equal-loudness contour at 70 phons. A comparison of the ASA B-weighting curve with the curve supplied by Fletcher and Munson reveals that both are horizontal at $70 \mathrm{db}$ between 400 and $1600 \mathrm{cps}$. At $200 \mathrm{cps}$, the former prescribes an intensity of $72 \mathrm{db}$ whereas the latter has an ordinate of $74 \mathrm{db}$. So, if anything, the ASA curve undercorrects for reduced sensitivity to the 200-cycle tone, which should therefore be equal or slightly lower in loudness in comparison with the three higher tones.
Each of the four frequencies was presented three times at each of three durations -1 sec., 2 sec., and 3 sec. Three random sequences of 36 tones were drawn up with the restriction that each successive set of 12 (to be referred to as a "phase") contained each combination of a frequency and a duration once. These three sequences and their inverses were used with approximately equal numbers of Ss.

The Ss were all male undergraduates attending elementary summer-session courses in psychology. The data from 49 Ss were left for analysis, after 23 had been discarded for having alpha waves more than $95 \%$ or less than $50 \%$ of the time or because interference made the tracings unclear.

$S$ was seated in a comfortable chair in a darkened room and was instructed to keep his eyes closed. After each tone, $E$ waited until alpha waves had reappeared before manually triggering the Hunter timer in order to bring on the next tone. The interstimulus interval varied between 3 sec. and 20 sec., apart from a few trials on which it was between 2 and $3 \mathrm{~min}$.

Resulis

The duration of desynchronization could notbe measured for 60 out of the 1,764 stimulus presentations, usually because the pen went out of range. Missing data were therefore inserted, and degrees of freedom adjusted, according to the procedures prescribed by Anderson (1946).

The mean desynchronization durations of primary interest are displayed in Figs. 1 and 2. The quadratic

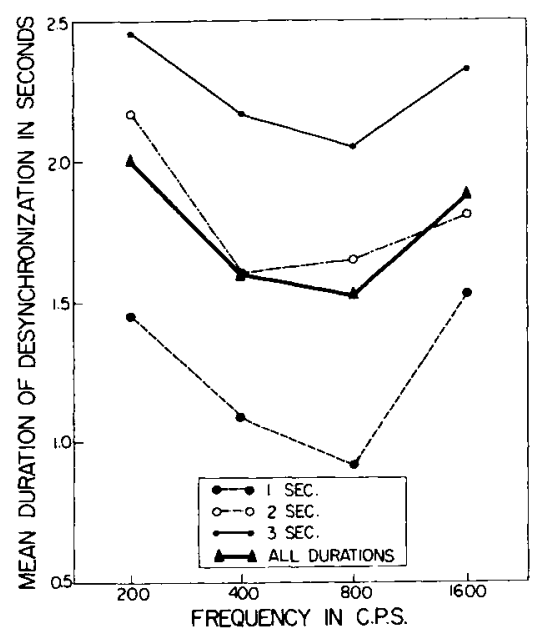

Fig. 1. Mean desynchronization duration as a function of acoustic frequency. 


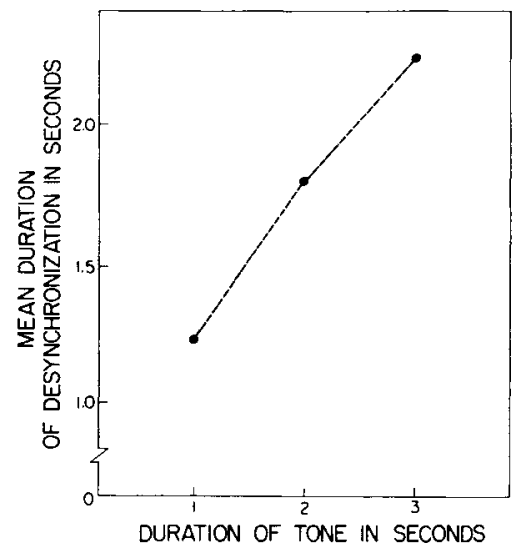

Fig. 2. Mean desynchronization duration as a function of stimulus duration.

component of the differences due to frequency is significant $(F=38.03, \mathrm{df}=1 / 1445, \mathrm{p}<.001)$, but the linear component and the deviation from quadratic trend are not. The linear component of the differences due to stimulus duration is significant $(F=181.02$, $\mathrm{df}=1 / 1445$, $\mathrm{p}<.001$ ), but the deviation from linearity is not.

\section{Discussion}

The mean desynchronization durations fell a little short of the stimulus durations (see Fig. 2). Alpha waves often resumed before the tone ended or appeared in brief bursts while the tone was on. It is interesting that there was a rectilinear relation between desynchronization and stimulus duration.

Various hypotheses might be advanced to explain the U-shaped function that connected desynchronization duration with acoustic frequency. The hypothesis that the intensification of the orientation reaction as the extremes of the frequency range are approached may reflect differences in relative frequency of occurrence, and thus in novelty, can be rejected. The lower half of the frequency range used in the present experiment includes the compass of the human voice. The first formant in closed vowels pronounced by male speakers is commonly around $200 \mathrm{cps}$ (Peterson, 1951), while the highest note that a soprano can normally reach is around 1,000 cps.

Two other kinds of hypothesis might account for the effect. First, a S might, either through natural selection or through learning, be more susceptible to arousal by high-pitched and low-pitched tones than by tones of intermediate pitch because the former are more frequently associated with events of biological importance (squeals of pain, thuds from collisions, etc.). Another possibility is that the U-shaped curve in Fig. 1 represents the resultant of two opposite trends. One would be a tendency (inherited, learned, or due to differential novelty) for the magnitude of the orientation reaction to increase with pitch. The other would be a tendency, due to conditioned affective responses, for the orientation reaction to become more intense as the frequency with which a particular pitch occurs in human speech increases.

It would seem from our data that the special emotional effect of a high note in music, e.g., at the climactic point of a musical phrase, is unlikely to be due to an effect of pitch as such, since most music belongs to the sector of the frequency spectrum within which pitch and arousal value were inversely related. This effect is more likely to depend on the relative novelty or surprisingness of a note that is higher than any heard during the last few bars. This suggestion is corroborated by the fact that relatively novel or surprising notes within the frequency band of the notes that have just been heard, i.e., chromatic notes, seem to be at least as a rousing.

\section{References}

Anderson, R. L. Missing-plot techniques. Biometr. Bull., 1946, 2, $41-47$.

Beriyne, D. E. Conflict, arousal and curiosity. New York: McGrawHill, 1960.

Berlyne, D. E., \& McDonnell, P. Effects of stimulus complexity and incongruity on duration of EEG desynchronization. $E E G$ clin. Neurophysiol., 1965, 18, 156-161.

Fletcher, H., \& Munson, W. A. Loudness, its definition, measurement and calculation. $J$. Acoust. Soc. Amer., 1933, 5, 82-108.

Peterson, A. P. G., \& Gross, E. E. Handbook of noise measurement. West Concord, Mass.: General Radio Co., 1963.

Peterson, G. E. The phonetic value of vowels. Language, 1951, $27,541-553$.

\section{Notes}

1. This investigation was supported by Research Grant MH-06324 from the National Institute of Mental Health, United States Public Health Service, and by Grant No. 70 from the Ontario Mental Health Foundation.

2. The authors are indebted to Sharon Lazare and Paul McDonnell, who carried out pilot experiments and helped in the analysis of the data. 